\title{
Evaluation of the energy efficiency of an internal blind containing PCM
}

\author{
Michat Musial, ${ }^{1, *}$ \\ ${ }^{1}$ Department of Building Engineering, Rzeszów University of Technology, Poznańska Street 2, \\ 35-084 Rzeszów, Poland
}

\begin{abstract}
This article presents the possibilities of using phase change materials for the modernization of transparent partitions and elements functioning with them. The author draws attention to the possibility of reducing the energy costs of the building, by increasing the thermal capacity of the internal window blinds. The article draws attention to many factors related both to the properties of PCMs themselves, the place of application and climatic conditions that may affect the effectiveness of the entire solution. To assess the energy efficiency of the abovementioned shutter, field tests were carried out in an isothermal test chamber. The article presents the results of the conducted research, showing the advantages and disadvantages of the considered solution. A large number of scientific papers, in which the possibilities of using phase change materials for the modernization of transparent partitions are presented, apply only to the modernization of glazing. In this context, this work presents a different approach to the issues of using phase change materials in construction.
\end{abstract}

\section{Introduction}

Over the last years, one can observe a tendency to design and build more and more energyefficient buildings. The improvement of the energy efficiency of a building can be achieved by limiting heat losses and more efficient use of profits from solar radiation, by the transparent partitions. Transparent partitions have a small heat capacity in relation to the opaque partitions. The result may be high daily amplitudes of window temperatures caused by the variability of atmospheric conditions. This may cause overheating of adjoining rooms during the day and overnight cooling.

A large thermal capacity of building partitions can be obtained by building them from materials with a high specific heat. In the works [1-2] the functioning of collectoraccumulation walls was presented, whose massive storage wall stabilizes daily changes in the air temperature inside the adjacent room.

A common method, used since the 1970s, increasing the thermal capacity of all building partitions is the use of phase-change materials. In the scientific work [3-9] the presented solution used PCM to be modified transparent partitions. The above substances were used in cooperation with glazing as well as blinds and external blinds [10, 11].

*Corresponding author: mmusial@prz.edu.pl 
Silva and others in [10] presented the results of experimental research on the blind, containing in its structure PCM RT 28 and a reference blinds without PCM. The blinds were elements cooperating with windows of large-scale polygon research chambers. The stand functioned during the heating season in a Mediterranean climate. The results presented in the paper indicate a stabilizing effect of air temperature in part with PCM, relative to the reference one. In addition, researchers observed a reduction in the peak temperature of glazing and air inside the chamber relative to the reference chamber.

In [11], Esam and Alawadhi conducted research and assessment of the type of PCM used and its quantity on its energy efficiency in internal blinds. The tests were carried out in polygonal test chambers, which had glazed on the south side. On the basis of the conducted research, the authors believe that the PCM used in blinds has a significant impact on their temperature values. The melting temperature should be close to the maximum values occurring at the PCM application site. In turn, its quantity should be so large that it does not completely melt PCM during the day. The decrease in energy consumption in part from PCM, noted by the authors, was at $23.29 \%$.

In [6] Liu et al., Presented the results of research and numerical analysis of selected glass packages modified with phase-change materials with melting temperatures of $14-16^{\circ} \mathrm{C}, 16-18^{\circ} \mathrm{C}, 18-20^{\circ} \mathrm{C}$ and thicknesses $4-50 \mathrm{~mm}$. The research was carried out in winter in north-east China. Based on the experimental research carried out and subsequent numerical simulations, the researchers formulated the following conclusions. With the increase of PCM layer thickness from $4 \mathrm{~mm}$ to $50 \mathrm{~mm}$, at the glass surface, the total amount of energy transmitted decreases by $109,1 \%$, while the amount of transmitted solar energy decreases by $86.1 \%$.

However, an increase in the thickness of the PCM layer may not affect the proportional increase in temperature on the inner surface of the pane and the total energy permeable by it. In addition, increasing the thickness of some PCMs can lead to a reversal of the change in the total value of energy transferred through the glazing. For the tested combinations, the authors indicated the thickness of PCM 12-30 $\mathrm{mm}$ with a melting point of $14-16^{\circ} \mathrm{C}$ for the most effective at the location considered.

In [7] Li, Sun, Zou, and Zhang, presented the results of tests in which the influence of the applied PCM in the inner chamber of the window pane 3 glass window 2 chamber was tested against the reference window without PCM. The obtained results indicate a decrease of the glass window peaks on the inside of the window by $5,5^{\circ} \mathrm{C}$. In turn, rainy days have seen favorable stabilization of indoor air temperature.

Obtaining the assumed energy effects depends on the selection of the appropriate phasechange material, thermal conditions prevailing at the place of application and thermal conductivity parameters of their surrounding materials.

In the works $[3,4]$ it was pointed out that in order to limit the cooldown of the barrier, the PCM should be located on the inside of the barrier. In turn, to reduce overheating of the barrier, PCM should be used from the outside of the partition.

In addition, the authors of [11] Esam and Alawadhi believe that the most efficient use of PCM latent heat in the context of stabilizing daily changes in temperature, air temperature or building elements is when the phase transition temperatures are close to the maximum occurring at the place of application.

An important aspect of the thermal work of thermal work of PCMs is the change in their volume during phase transformations. To minimize the resulting stresses, the abovementioned substances are coated with polymeric matrices, forming stable capsules or microcapsules. The undoubted disadvantage of the above-mentioned solution is the reduced thermal conductivity of the entire composite described by Şahan, Paksoy in [12]. Phase-change materials, in particular organic compounds, are characterized by relatively low thermal conductivity in the solid state The values of heat conduction coefficients 
oscillate in the range of $\lambda=(0.1-0.3) \mathrm{W} / \mathrm{m} \cdot \mathrm{K}$, the above properties were presented by Vogel in [13]. The possibility of increasing the thermal conductivity of the above mentioned materials may be the use of a nanocomposite of copper and titanium deposited in the methyl ester (HNPCM). In [14], Kumara showed nearly a 70\% increase in thermal conductivity of selected PCMs.

Another very important aspect is the unchanging properties of PCM over time. In [15] Behzadi and Farid presented the results of research, where selected PCMs: a mixture of paraffins and an ester were subjected to multiple changes in the state of aggregation. It was noted that in the case of a paraffin mixture, the more volatile constituents of the mixture were evaporated, which significantly changed their properties: the enthalpy of melting/freezing increased from $134 \mathrm{~J} / \mathrm{g}$ to $170 \mathrm{~J} / \mathrm{g}$ and the peak melting temperature increased from $21^{\circ} \mathrm{C}$ to $28^{\circ} \mathrm{C}$.

The author, aware of the disadvantages and advantages of PCMs and the ranges of their effective applicability, considered it necessary to conduct polygon tests on the internal window-blind containing phase-change material in its structure, which is the subject of a patent application [16].

\section{Materials and Method}

\subsection{Phase-change material}

In the present studies used commercial phase change material RT 28 (mixture of paraffins), manufactured by Rubiterm $\mathrm{GmbH}$, the value of enthalpy of fusion and solidification interval of $\Delta \mathrm{H}_{\text {fus }}=220-225 \mathrm{~J} / \mathrm{g}, \mathrm{m} . \mathrm{p} .=28^{\circ} \mathrm{C}$ and a solidification temperature $=21^{\circ} \mathrm{C}$.

A water dispersion of the Osakryl OB copolymer produced by Ciech was used to make the polymer matrix.

\subsection{Window blind}

The window blind was made of 12 aluminum profiles with external dimensions of $8 \times 79 \times 820 \mathrm{~mm}$. Aluminum profiles have been covered with black matte paint. Each profile was sealed using epoxy resin Epidian 6 with hardener Z1.

\subsection{Measuring apparatus}

- Precise recorder ALMEMO 2890-9;

- including software heat meter Type 117 epoxy 100x30x1,5 mm;

- order no FQAD17T;

- thermo steam with a cord LT 019008;

- pyrometer ALMEMO;

- energy consumption meter Volcraft 4000.

\subsection{Research position}

The test stand is an isothermal chamber with dimensions of $191 \times 283 \times 270 \mathrm{~cm}$, functioning in real conditions of external climate. The chamber has two identical glazing located on the south side. The other partitions have thermal insulation in the form of a $20 \mathrm{~cm}$ layer of mineral wool.

The inside chamber has been divided into two identical parts. The partition between them was made of $16 \mathrm{~cm}$ layer of extruded polystyrene. Each part of the chamber has an independent oil heater, connected to its own energy consumption meter and its own thermoregulator. A photograph of the test stand is shown in Figure 3. 
In addition, at each of the windows, on the inside of the chamber, a vertical window shutter made of identical aluminum profiles was installed. Each of the blinds on one side was covered with an absorption coating and on the other hand with a reflective coating. Inside the profiles of one of the blinds, RT 28 phase-changing material was placed, while extruded polystyrene was placed inside the reference shutter. The photograph of the prepared roller blind is shown in Figure 2.

In the stand described above recorded the values of glazing temperatures and the density of the flowing heat flux from the inside of the chamber. Additionally, the temperature of the internal air on both sides of the chamber was recorded, the density of the heat flux flowing through each of the blinds as well as the temperature of the outside air and the intensity of solar radiation. A detailed view of the chamber and the location of the sensors is presented in the Figure 1.

Field tests at this position was conducted from November 2016 to April 2017 in Rzeszów. In order to be able to observe differences in the thermal functioning of baffles associated with the application of phase-change material, the measurements were carried out with a 10-minute time step.

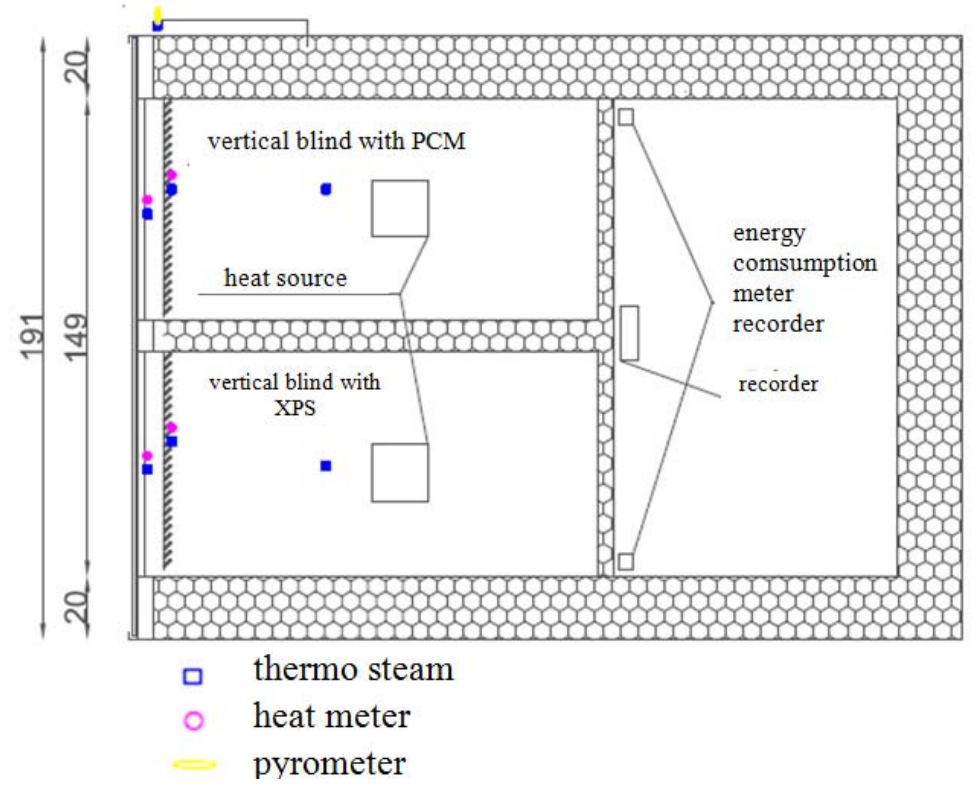

Fig. 1. Plan polygonal test chamber. 


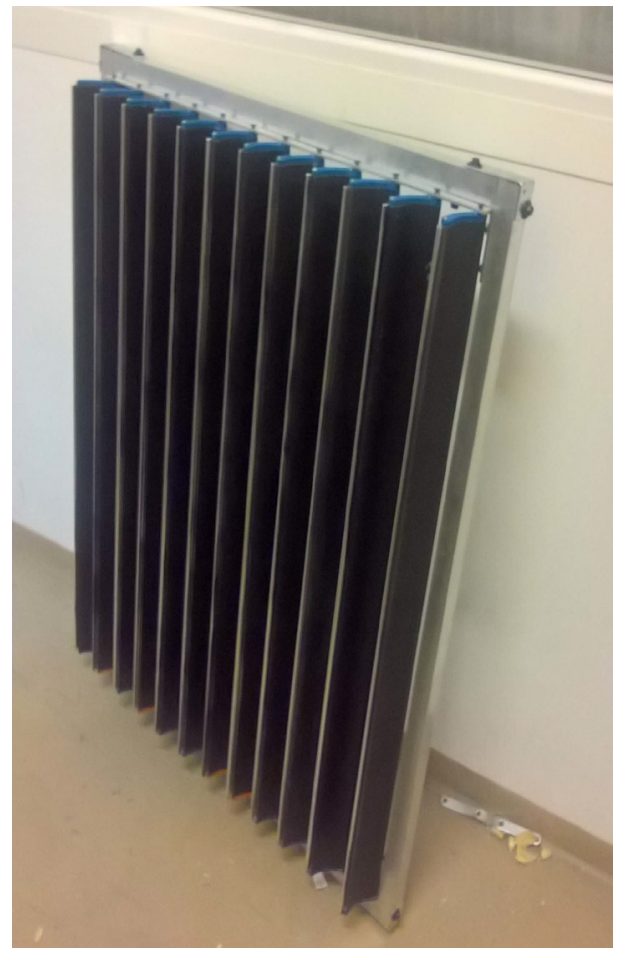

Fig. 2. A photo of a vertical blind.

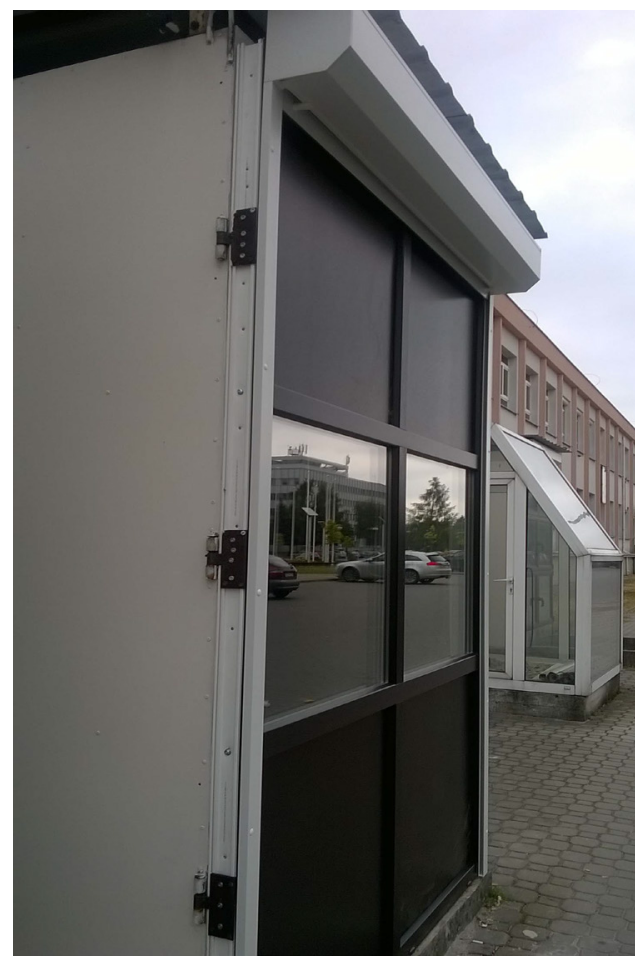

Fig. 3. A photograph of a polygonal test chamber.

\section{Results}

The results of the measurements carried out in April for randomly chosen solar days are presented below in Figures 4 to 7.

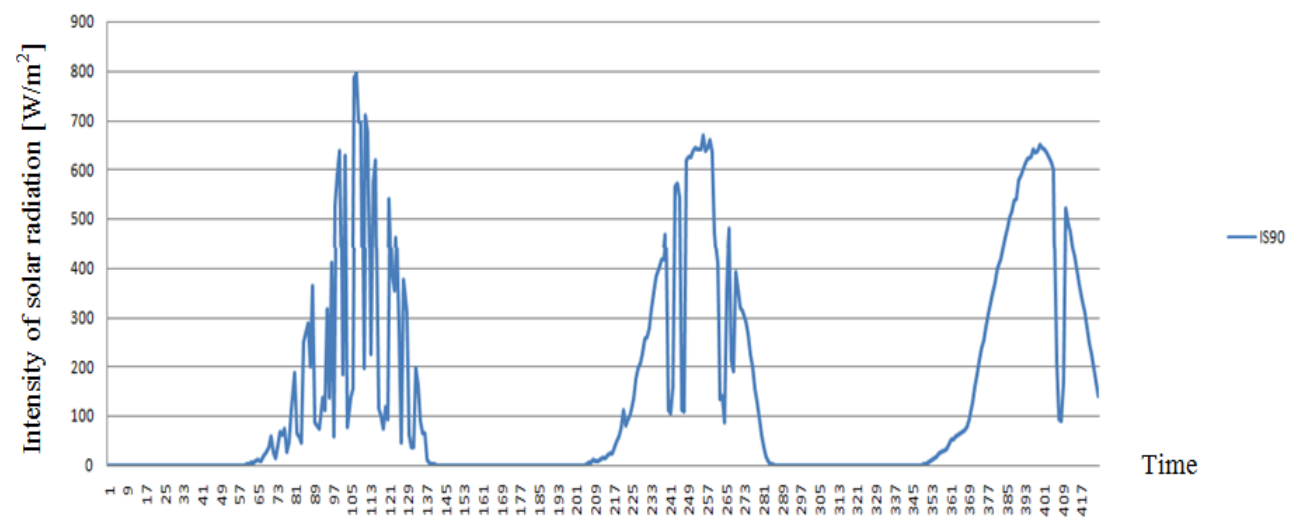

Fig. 4. Chart of the intensity of solar radiation.

The chart above has been prepared on the basis of solar radiation measurements made for southern exposure at an angle of $90^{\circ}$ to the ground plane. 


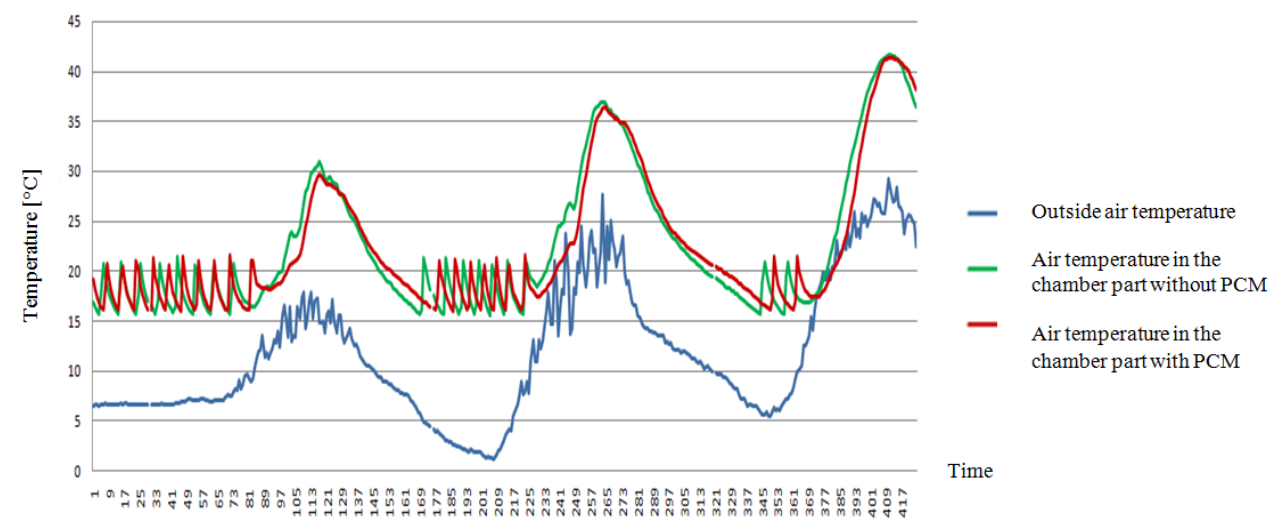

Fig. 5. Temperature chart of external and internal air, on both parts of the chamber.

During the tests, a slight reduction of the peak air temperature values was observed in the part of the chamber with the PCM shutter against the part with the reference shutter. Also, a slight shift in the phase of diurnal changes in the internal air temperature in the part with the PCM shutter against the air temperature from the chamber part with the reference blind was also found.

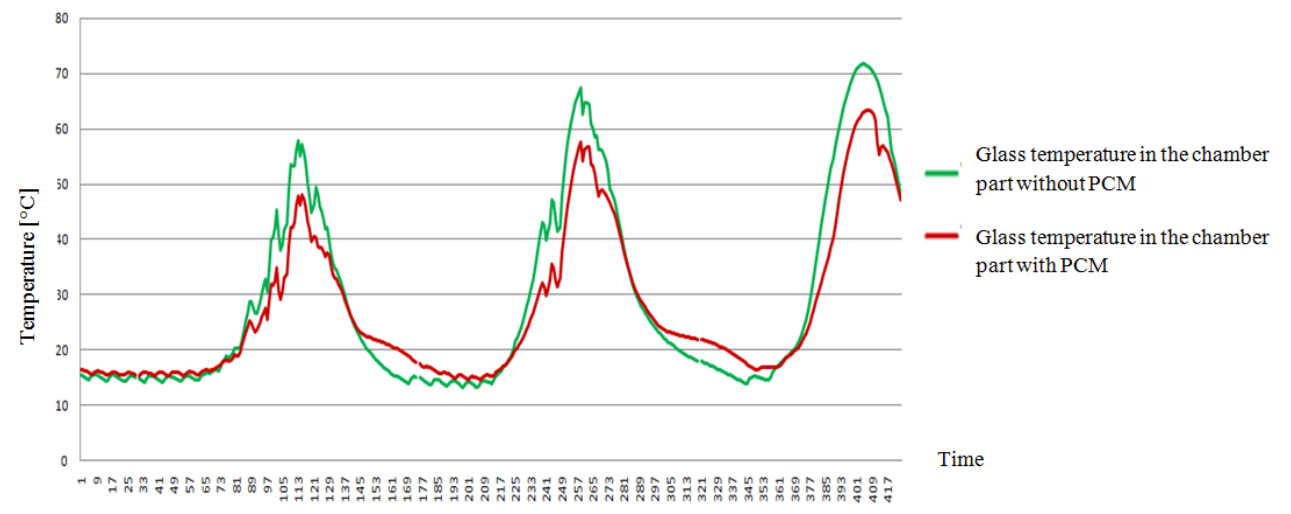

Fig. 6. Chart of the glass temperature from the inside of each part of the chamber.

The obtained changes in the temperatures of the inner surfaces of glass panes are presented in the graph Fig. 5. It is possible to observe a significant, approx. 10-degree decrease in the peak temperature values of the inner surface of glass panes. It is also possible to reduce the temperature drop in the inner surface of the window pane at the PCM blind relative to the temperature of the glass in the reference part at a temperature of $21-22^{\circ} \mathrm{C}$, in which there is a solidifying PCM. The above release of the accumulated heat by PCM results in a longer cooling time of the inner surface of the glass at the blinds with $\mathrm{PCM}$, up to $20^{\circ} \mathrm{C}$, for about $3-4$ hours. In turn, a noticeable delay in heating the glass at the shutter with PCM, relative to the glass at the reference blind, was observed only at temperatures of about $27-28^{\circ} \mathrm{C}$, which coincides with the melting point of PCM and causes a 20-30 minute phase shift of the chart. 


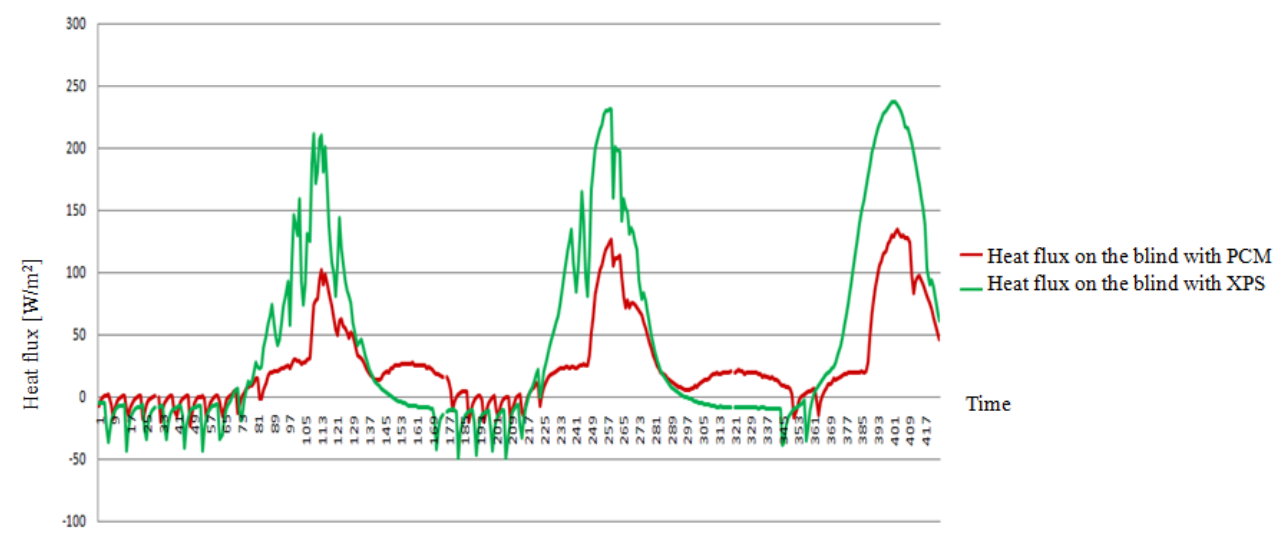

Fig. 7. Chart of heat flux density on internal blinds.

In the chart Fig.7. the changes in the density of heat flux over time are shown for the blinds measured on the closed surface from the inside of the chamber. One can notice both the reduction of the peak values of the heat flow flux during the sunny day by the PCM blind against the reference, as well as the reduction of the amount of energy flowing through the PCM blinds; compared to the reference blind. During the night after a sunny day, it is possible to observe a change in the trend of the flow of heat from the blinds with PCM when the temperature of solidification is reached. A noticeable change in the direction of the heat flux measured on the surface of the shutter with PCM takes place with a few hours delay relative to the reference blind.

In Fig. 8 and Fig.9 is a chart showing the consumption of electricity needed to power oil heaters in a part of the chamber with a PCM blinds and parts with a reference blinds. For the presented sunny days, the energy consumption in the PCM blind part as compared with the reference part is lower by $7,8 \%$.

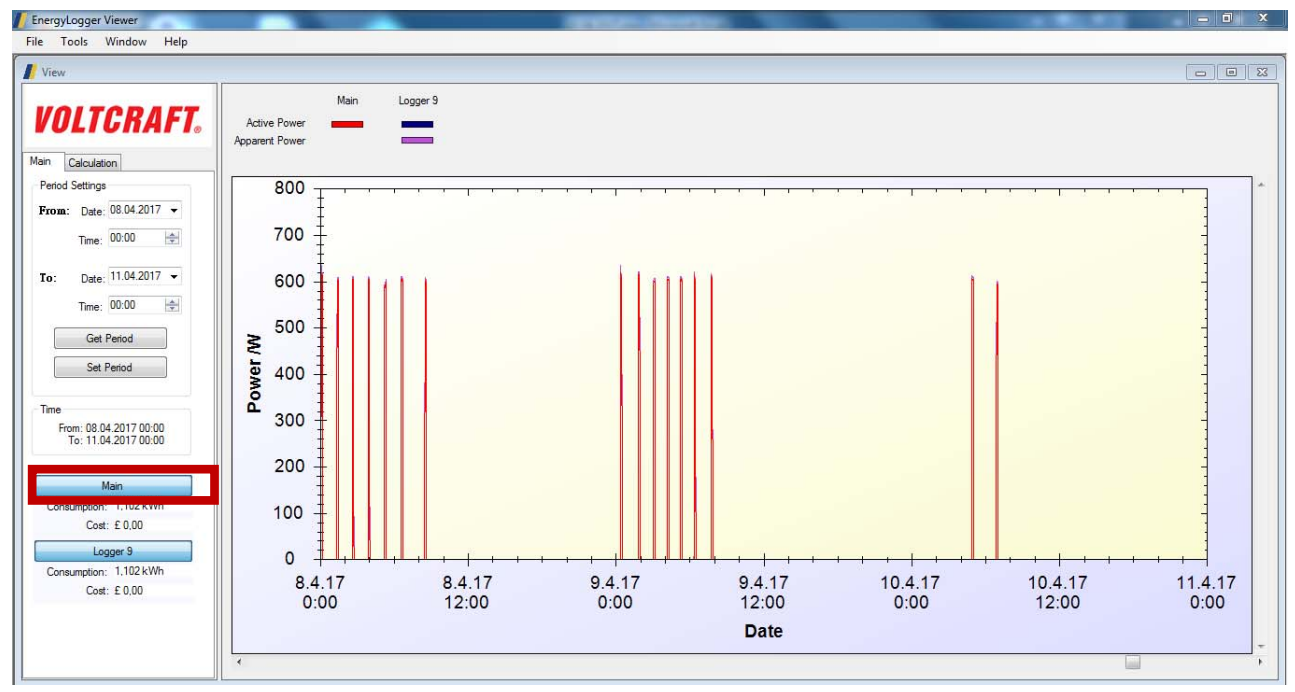

Fig. 8. Chart of energy consumption of an oil heater on the side with a PCM blind. 


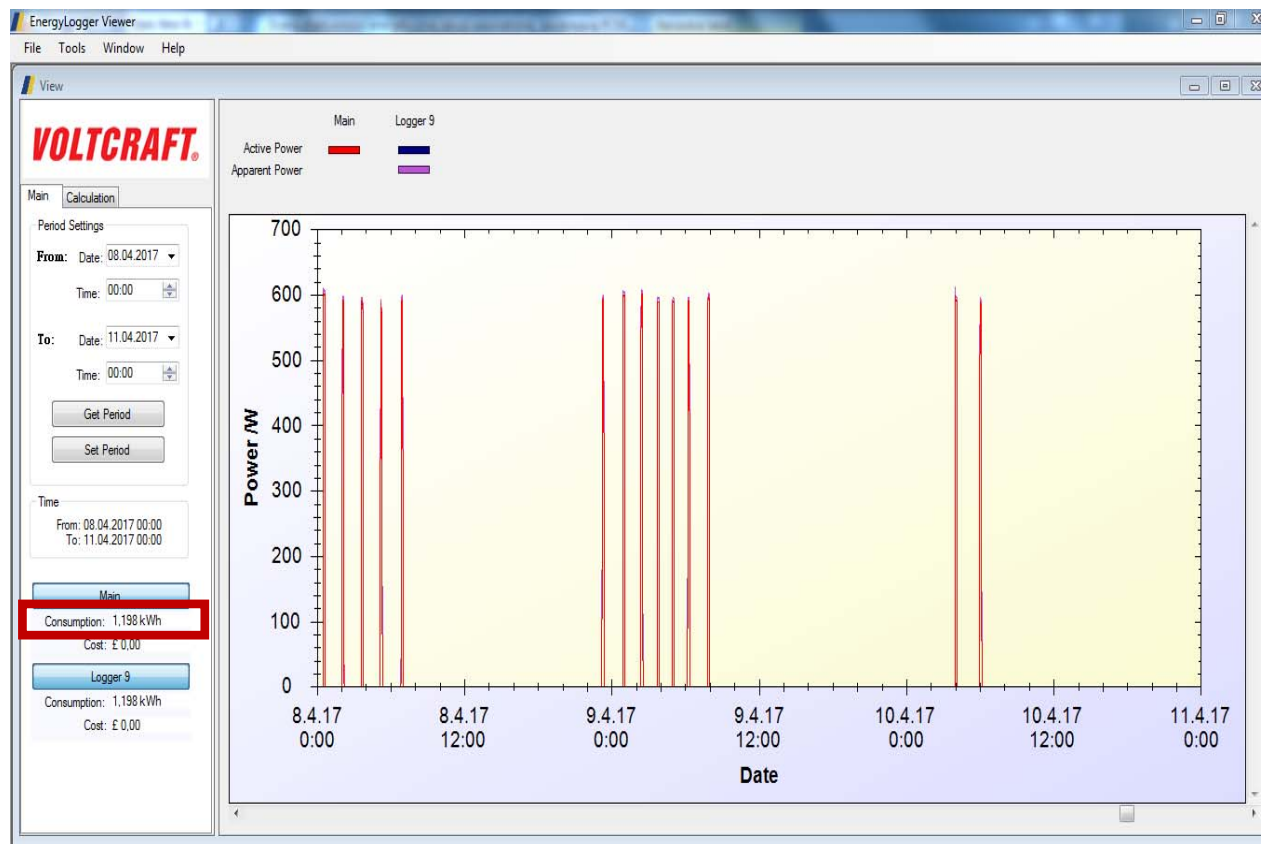

Fig. 9. Chart of energy consumption of the oil heater on the side with the reference blind.

\section{Conclusions}

On the basis of the conducted field tests, it was found that the temperature peaks of the glazing and inner blinds were reduced on sunny days in relation to the glazing and reference blinds. There was also a reduction in energy consumption, in the part of the PCM chamber, needed to maintain a constant air temperature during sunny days in relation to the reference part of the chamber. On the other hand, for the whole considered period, an increase in energy consumption on the side of the blind with PCM in relation to the part with the XPS blind was found. The above fact is caused by a small number of sunny days in the heating season in question. Although the author did not show a reduction in the costs of reheating the chamber with the PCM blinds during the heating season relative to the standard blind, the above fact may take place in a climate with a greater number of sunny days. The above solution can be used to reduce the cost of cooling rooms outside the heating season. This solution would be more effective when coating aluminum profiles with a reflective coating.

\section{References}

1. J. Szyszka, J. Kogut, I. Skrzypczak, W. Kokoszka, IOP Conf. Ser.: Earth Environ. Sci. 95042018 (2017)

2. P. Ochab, W. Kokoszka, J. Kogut, I. Skrzypczak, J. Szyszka and A. Starakiewicz, IOP Conf. Ser.: Earth Environ. Sci. 95042017 (2017)

3. M. Musiał, M. Kaczmarzyk, JCEEA 63 (2/I/2016), 171-178 (2016)

4. L. Lichołai, M. Musiał, JCEEA, 63 (4/16), 329-338 (2016)

5. K. A. R. Ismail, J. R. Inter. J. Energ. Res. 21, 1241-1255 (1997)

6. C. Liu, Y. Wu, D. Li, Y. Zhou, Z. Wang, X. Liu, J. Build. Eng. 11, 87-95 (2017) 
7. S. Li, G. Sun, G. Zou, X. Zhang, Cit. Soci. 27, 15-22 (2016)

8. L. Lichołai, J. Krasoń, P. Miąsik, A. Starakiwicz, JCEEA, 64 (1/17), 495-504 (2017)

9. J. Krasoń, JCEEA, 61 (3/II/14), 297-306 (2014)

10. T. Silva R. Vicente, F. Rodrigues, A. Samagaio, C. Cardoso, Energ. Build. 88, 110-121 (2015)

11. M. Esam, E. M. Alawadhi, Energ. Build. 47, 421-429 (2012)

12. N. Şahan, H. Paksoy, Sol. Energ. Mat. Sol. C. 174, 380-387 (2018)

13. J. Vogel, Preparatyka organiczna, (Wyd. Nauk.-Tech, Warsz. 2006) (in polish)

14. K. R. S. Kumara, R. Parameshwaran, S. Kalaiselvam, Sol Energ. Mat. Sol. C, 171, 148-160 (2017)

15. S. Behzadi, M. M. Farid, App. Energ. 122, 11-16 (2014)

16. L. Lichołai, M. Musiał, J.Szyszka Pat. App. EP3091166-A1 (2015) 